\title{
Improving The Response Time of Load - Frequency Control of Gasturbine in a Nigerian Refinery
}

\author{
C.A.Ugoh, M. Olubiwe, D.S Inaibo \\ Department of Electrical and Electronic Engineering, \\ Federal University of Technology, \\ Owerri, Nigeria.
}

\begin{abstract}
Gas turbine as a fast response unit, suitable for improving transient response of the power system at any time when there is problem usually from $15-20$ seconds in some cases has been lost to some unforeseen issues due to energy demand, lack of control measures, improper attention , relatively high constraints in increasing and decreasing the power output during the nominal operation. Refinery which is one of the outfit of Nigeria National Petroleum Corporation (NNPC) is one of the most important sources of revenue to the federal government of Nigeria. Hence efficient energy and stability of energy is very paramount. This paper has presented a control system for improving the response time of speed/load-frequency of a typical gas turbine in a refinery in Nigeria. The objective of the study is to reduce the response time of the Gas turbine when there is abnormal increase in load or transient in the system, to enhance stability. . In order to realize the objective, the dynamic equations of a single shaft heavy duty gas turbine (HDGT) were obtained for loadfrequency control operation. The dynamic equations were transformed into their equivalent simulink model in Matlab/Simulink environment. A lead phase compensator was initially developed for the control loop and maintaining the optimized performance specification, a proportional, integral and derivative (PID) controller was developed in Matlab/Simulink environment. The governor speed droop of 4\% was used for the simulation. An analogue controller was designed. The essence of the analogue controller is only to demonstrate the fact that the control loop developed in this context used a permanent droop of $4 \%$ which gave the speed governor gain of 25 (per unit MW/per unit speed). Hence the optimized compensator performance specifications were then maintain and used to develop a PID structure with the same performance but with improved tracking. The designed PID controller was improved by adding a low pass filter to the derivative component. This greatly improved the transient response time. The simulations results showed that the introduction of the nonlinear PID controller significantly improved the transient response time of the system from 20 s to 10.5s. This was achieved by introducing a nonlinear PID controller as part of the control loop, and consequently improved the performance thereby reducing the response time greatly.
\end{abstract}

Key words: Improving, Response-time, controller, Gas-turbine, frequency

\section{INTRODUCTION}

Gas turbines have become more common as a power generating engine due to their flexibility and low specific investment costs as witnessed over the last decades.
Development of gas turbines for power generation has gone simultaneously with the development of new gas turbines for use in aircraft engines and refineries. This increase in the proportion of gas turbine and combined-cycle units in power generation grids will affect the grid characteristics because of the gas turbine performance [1]. In a power grid system, load frequency control (LFC) plays an essential role. It provides better conditions for power exchange and supply in trading electricity. Delay in such systems could reduce system performance and even cause frequency or other parameters instability within the system [2]. The dynamic behavior of the power systems and also their effects in industrial loads depend on disturbances and in particular on changes in the operating point [3]. The goal of the LFC is to maintain zero steady state errors in a multi area interconnected power system or stand alone units. Furthermore, the power system should fulfill the proposed dispatch conditions [4].Accurate modeling of power system components is required in the study of power system stability. The abundance of natural gas, couple with the relatively short time for planning to commercial operation, has contributed to the increase in use of gas turbine owing to the removal of government control from power market environment. Refineries being one of the important revenue generating parastatals of the government need to have efficient power generation to sustain productivity and to reduce downtime.

Governor and turbine are relevant components of the generating units. The gas turbine engine is a complex assembly of different components such as compressors, turbines, combustion chambers, etc., designed on the basis of thermodynamic laws [5]. Gas turbines usually consist of an axial compressor, a combustion chamber and a turbine operating under Brayton cycle [6]. These three elements make-up the thermal block and are complemented by the air intake system, the exhaust system, auxiliaries and controls.

The gas turbine as a fast response component is designed for improving transient response of the power system, but this function has been lost to some extents due to excessive energy demand. This problem also arises as a result of the relatively high constraints in increasing and decreasing the power output during the nominal operation. This problem most often persists if not checked or controlled. This paper is a contribution to the systematic analysis of load-frequency 
control concepts for single shaft heavy duty gas turbines in aNigerian refinery. It is concerned with the improvement of the transient response time of load-frequency control of a gas turbine using a nonlinear proportional, integral and derivative (PID) controller integrating a low pass filter.

\section{MODEL DYNAMICS OF GAS TURBINE}

A typical gas turbine model has basically three control loops as shown below. The control loop, which is mainly active when the gas turbine is operating at nominal conditions is the load-frequency control (LFC). The input to this control is the speed/load set-point. The control section is restricted by the minimum fuel limit. The speed control or LFC is also the most important aspect during stability studies. The dynamics of the parts of the gas turbine that are essential in analyzing the transient characteristics of a load-frequency control in gas turbine are considered in this work and are presented below.

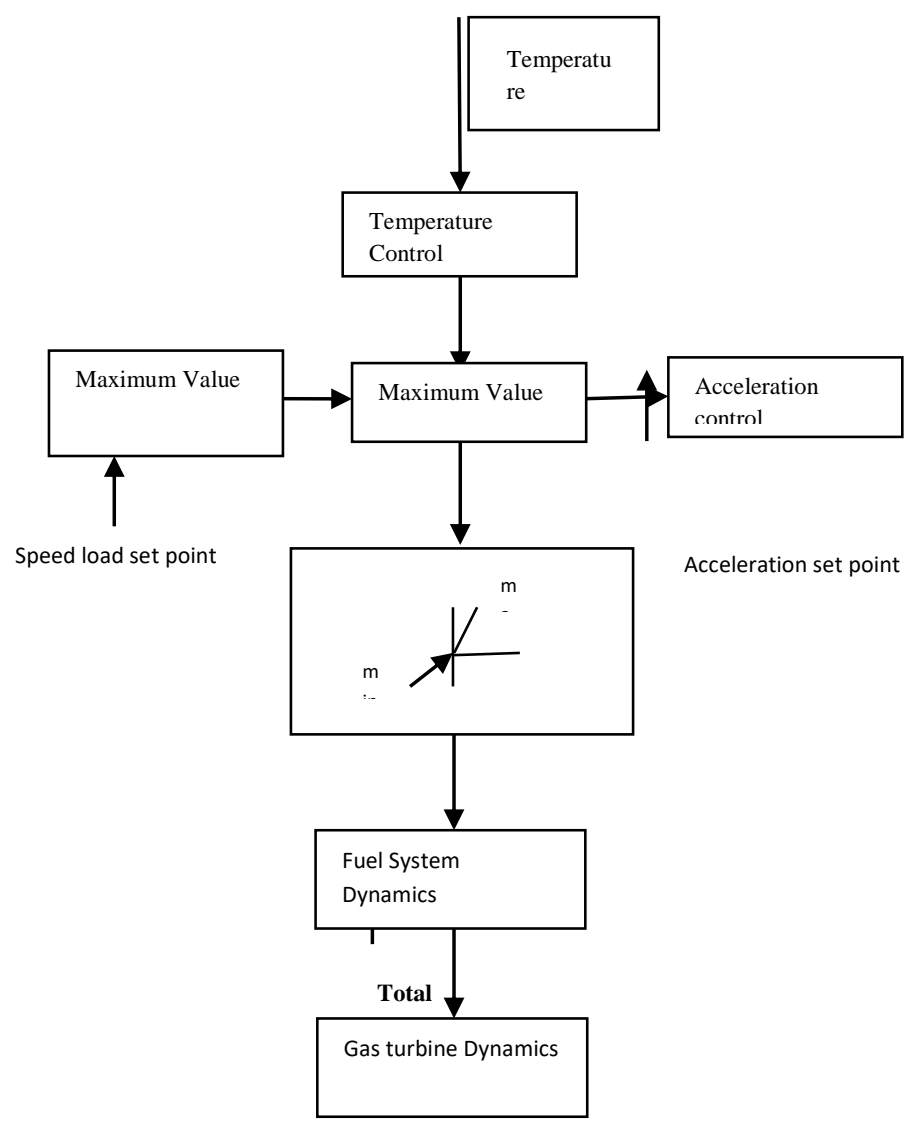

Fig. 1: Representation of gas turbine model

\section{A. $\quad$ Fuel System Dynamics}

The fuel system consists of the fuel valve and actuator. The amount of fuel injected for a gas turbine is determined by a valve positioner controlled by the turbine speed controller. The valve positioner transfer function can be represented by the following transfer function [7].

$$
V(s)=\frac{a}{b s+c}
$$

where $a, b$, and $c$ are the valve positioner constants.

The fuel system actuator transfer function is:

$$
F(s)=\frac{1}{T_{f c} s+1}
$$

where $T_{f_{c}}$, is the fuel system actuator time constant in seconds.

The block diagram of the fuel system is represented in Fig. 2.

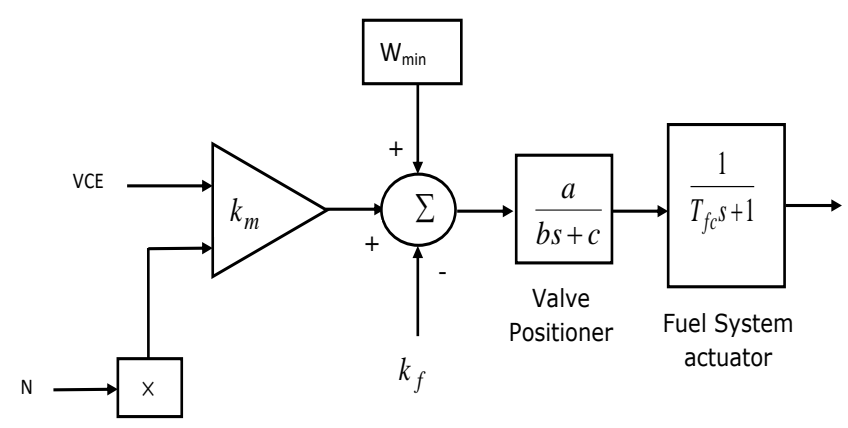

Fig. 2: Block diagram of the fuel system Dynamics

B. Compressor-Turbine Dynamics

The burning of the fuel in the combustor is presented by the following function:

$$
e^{-s T_{C R}}
$$

where $T_{C R}$ is the combustion reaction time delay constant in seconds.

The transfer function of the hot computation gas expansion is expressed as follows:

$$
T(s)=\frac{1}{T_{C D} s+1}
$$

where $T_{C D}$ is the compressor discharge volume time constant in seconds.

The mechanical torque produced which drives the electric generator is presented by the following equation [7].

$$
T_{m}=A+B \dot{m}_{f}+C(1-N)
$$

where $\dot{m}_{f}$ is the fuel nominal flow rate, $A$ and $B$ are the coefficient of output torque which could be obtained by applying the actual data in Table 1.and $N$ is the per unit rotor speed. The value for $\mathrm{C}$ in the torque equation (5) varies between 0.5 and 0.67 for heavy duty gas turbine (HDGT) [8]. In this context, $\mathrm{C}$ is assigned a value of 0.5 . 


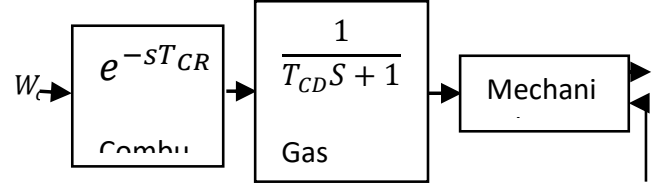

N

Fig. 3: Block diagram of compressor-turbine dynamics

\section{CASE STUDY OF SELECTED GE GAS TURBINE OF A REFINARY IN NIGERIA}

A 38MW single shaft heavy duty gas turbine (HDGT) of model GE whose design specifications are given in Table 1 is considered in this context. It uses natural gas or distillate as its primary operating fuel. In this context, the computations performed did not take into account the pressure loss in the entrance of air filters and also at combustor.

Table 1: Design Specifications of HDGT Selected

\begin{tabular}{|l|l|l|l|}
\hline Parameters & Symbol & Unit & Value \\
\hline Heat Rate & $\mathrm{H}_{\mathrm{R}}$ & $\mathrm{KJ} / \mathrm{Kwh}$ & 11302 \\
\hline Electrical power & $\mathrm{PGT}$ & $\mathrm{MW}$ & 33.4 \\
\hline Exhaust Temperature & $\mathrm{T}_{\mathrm{OE}}$ & ${ }^{0} \mathrm{C}$ & 538 \\
\hline Pressure Ratio & $\mathrm{PR}$ & - & 11.8 \\
\hline Fuel Flow & $\dot{m}_{n o}$ & $\mathrm{Kg} / \mathrm{s}$ & 139.1 \\
\hline $\begin{array}{l}\text { Compressor Discharge } \\
\text { Temperature }\end{array}$ & $\mathrm{T} \mathrm{CD}$ & ${ }^{0} \mathrm{C}$ & 343 \\
\hline
\end{tabular}

The design specifications in Table 1 are provided for nominal operating conditions. Table 2 provides typical operational data selected for computing the turbine and compressor efficiencies. The turbine and compressor efficiencies are inherently assumed to be constant in power, put near nominal operation [8].

Table 2: Typical Operating Data for Computing Turbine and Compressor Efficiencies

\begin{tabular}{|l|l|l|}
\hline Parameters & Unit & Value \\
\hline Out Put Power & $\mathrm{MW}$ & 30.2 \\
\hline Turbine Inlet Temperature & ${ }^{0} \mathrm{C}$ & 520 \\
\hline Exhaust Gas Temperature & ${ }^{0} \mathrm{C}$ & 200 \\
\hline Ambient temperature & ${ }^{0} \mathrm{C}$ & 26 \\
\hline Fuel flow & $\mathrm{Kg} / \mathrm{s}$ & 0.99 \\
\hline Exhaust Mass Flow & $\mathrm{Kg} / \mathrm{s}$ & 85.9 \\
\hline Lower Heating Value of Fuel (LHV) & $\mathrm{KJ} / \mathrm{Kg}$ & 43309 \\
\hline
\end{tabular}

The values of the efficiencies of turbine and compressor obtained using the parameters of Tables 1 and 2 were used to calculated the $\dot{m}_{f}, A$ and $B$ of the HDGT considered in this context. The detail analysis on how to calculate the efficiencies of turbine and compressor can be obtained in [8].

\section{A The mechanical torque}

In order to extract the parameters: $\dot{m}_{f}, A$ and $B$, the HDGT considered has been assumed to be operating at nominal speed. The mechanical output torque and the mechanical power would be the same. The calculated values of the parameters using the equations obtained from [8] are: $\dot{m}_{f}=$ $3.33 \mathrm{~kg} / \mathrm{s}, A=-0.4978$, and $B=1.5002$.

\section{$B \quad$ Configuration of the Control System}

The block diagram of the control system for realizing the objective of this work is shown in Figure. 4. In this work, the entire system is represented as a single input single output (SISO) system. The controller, the fuel system and the compressor-turbine assembly are all represented on the forward part.

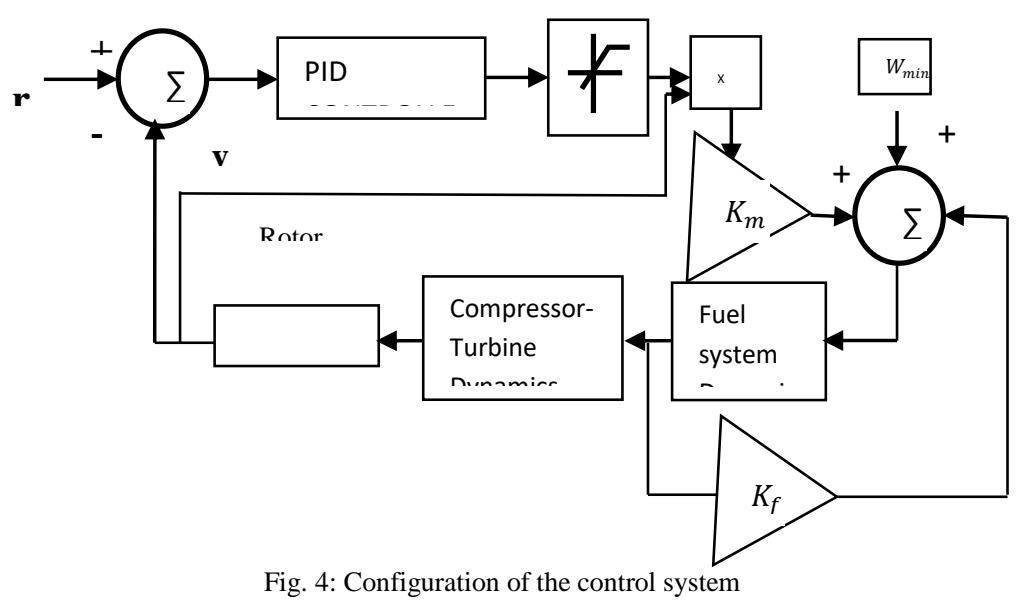

\section{CONTROLLER DESIGN}

During normal operating conditions, the speed/loadfrequency control is active. The input to the controller in this case is the speed error or deviation. An analogue compensator or a proportional, integral and derivative (PID) controller may be required. In this work, the load-frequency control has been isolated and studied separately and it is expected that gain of control should be the inverse of the droop. Hence, an analogue lead-phase compensator is first developed in this context and a PID structure of the controller is developed with the same performance criteria.

\section{A Analogue Compensator}

In this work, the controller is designed to maintain a reference speed. A nonlinear control approach has been adopted in this context to select the compensator parameters. This approach uses the Matlab/Simulink optimization toolbox. The gains of the compensator are constrained such that the system performance attains specifications of the transient response conditions. The constrained performance conditions are shown in Table 3

Table 3: Constrain performance conditions
\begin{tabular}{|l|l|}
\hline Performance condition & Values \\
\hline Rise time (s) & 0.2 \\
\hline Settling time (s) & 10 \\
\hline$\%$ Overshoot & 5 \\
\hline$\%$ Rise & 90 \\
\hline
\end{tabular}


The analogue compensator is given by:

$$
G(S)=\frac{W^{*} X s+W}{Y s+Z}
$$

The obtained optimized selected parameters of the controller obtained by constraining system to the specification are stated in Table 4.

Table 4: Selected gain parameters of the analogue compensator

\begin{tabular}{|l|l|}
\hline Parameters & Values \\
\hline $\mathrm{W}$ & 25.0 \\
\hline $\mathrm{X}$ & 0.2 \\
\hline $\mathrm{Y}$ & 1.0 \\
\hline $\mathrm{Z}$ & 5.0 \\
\hline
\end{tabular}

Substituting the parameters in Table 4 into Equation (6) yields:

$$
G(S)=\frac{5 s+25}{s+5}
$$

\section{B The Designed PID Controller}

The designed nonlinear PID controller is represented in equation (8). The controller was implemented using the Simulink PID block and the gains were selected by constraining the response of the system to meet the designed specifications. The values of the gains of the PID designed in this context are stated in Table 5.

Table 5: The gains of the designed PID controller

\begin{tabular}{|l|l|}
\hline Parameters & Gain \\
\hline $\mathrm{K}_{\mathrm{P}}$ & 609.760 \\
\hline $\mathrm{K}_{\mathrm{i}}$ & $7.683 \times 10^{4}$ \\
\hline $\mathrm{K}_{\mathrm{d}}$ & 112.805 \\
\hline $\mathrm{N}$ & 10 \\
\hline
\end{tabular}

$$
U(s)=K+\frac{I}{s}+\frac{D N s}{s+N}
$$

where $K=k_{p} E(s)=10, \quad I=k_{i} E(s)=1.26 \times 10^{-5}$, $D=k_{d} E(s)=1.85$, and $N=10$, which is the filter coefficient. This yield:

$$
U(s)=10+\frac{1.26 \times 10^{-5}}{s}+\frac{18.5 s}{s+10}
$$

The low pass filter in the PID controller will take care of disturbance that may affect the set point signal of the system and consequently eliminate cycling.

C Model Parameters and Numerical Values

\begin{tabular}{|c|c|c|c|}
\hline Parameter & Symbol & Unit & Values \\
\hline $\begin{array}{l}\text { Governor speed } \\
\text { gain=1/droop }\end{array}$ & $\mathrm{W}$ & p.u. & 25 \\
\hline $\begin{array}{l}\text { Governor lead time } \\
\text { constant }\end{array}$ & $\mathrm{X}$ & sec. & 0.2 \\
\hline Governor lag time constant & $\mathrm{Y}$ & sec. & 0.05 \\
\hline $\begin{array}{l}\text { Control mode (1=droop, } 0= \\
\text { isochronous) }\end{array}$ & $\mathrm{Z}$ & - & 1 \\
\hline Upper limit of fuel demand & $F_{\max }$ & p.u. & 1.5 \\
\hline Lower limit of fuel demand & $\mathrm{F}_{\min }$ & p.u. & 0 \\
\hline Valve positioned & $\mathrm{a}$ & - & 1 \\
\hline Valve positioned & $\mathrm{b}$ & - & -0.1 \\
\hline Valve positioned & $\mathrm{c}$ & - & 1 \\
\hline Minimum fuel flow & $\mathrm{W}_{\min }$ & - & 0.23 \\
\hline Fuel control time constant & $\mathrm{T}_{\mathrm{FC}}$ & sec. & 0.4 \\
\hline Fuel system feedback & $\mathrm{K}_{\mathrm{FB}}$ & - & 0 \\
\hline $\begin{array}{l}\text { Combustion reaction time } \\
\text { delay constant }\end{array}$ & $\mathrm{T}_{\mathrm{CR}}$ & sec. & 0.01 \\
\hline $\begin{array}{l}\text { Compressor discharge } \\
\text { volume time constant }\end{array}$ & $\mathrm{E}_{\mathrm{CD}}$ & sec. & 0.2 \\
\hline Turbine inertia constant & $\mathrm{T}_{\mathrm{t}}$ & sec. & 15.64 \\
\hline $\begin{array}{l}\text { Gas turbine torque bock } \\
\text { parameter }\end{array}$ & A & - & -0.4978 \\
\hline $\begin{array}{l}\text { Gas turbine torque bock } \\
\text { parameter }\end{array}$ & B & - & 1.5002 \\
\hline $\begin{array}{l}\text { Gas turbine torque bock } \\
\text { parameter }\end{array}$ & $\mathrm{C}$ & & 0.5 \\
\hline
\end{tabular}

The values of the parameters used for the simulation are given in Table 6.
Table 6: Model parameters and numerical values

\section{SIMULATION RESULTS}

The simulation of the control system was performed in Matlab/Simulink environment. The parameters used in the simulations are presented in Table 6. The simulations were performed to check the performance of the system based on the transient response of the rotor speed (or frequency) of a single-shaft heavy duty gas turbine (HDGT). This is done as at the time the controller was not in the control loop and when it was integrated into the loop for better comparison.. The simulation results during the time the controller was not in the control loop and when it was, were performed in the droop mode. This control mode is the operational mode by which the turbine is allowed to react to load variation by changing its speed. The droop of the gas turbine considered in this context is $4 \%$. This means that for every change of $1 \%$ rated speed, the load of the machine is expected to change by $25 \%$ of its rated load. In order to give an obvious demonstration of the effectiveness of the designed nonlinear proportional integral and derivative (PID) controller with a low pass filter, simulations were performed for the designed analogue compensator such that the constrained conditions were then maintained and used to design the nonlinear PID controller. The nonlinear PID controller was implemented in two phases. In the first case the system was implemented with no low pass filter, and in the second case with a low pass filter whose coefficient, $\mathrm{N}=10$ was integrated. 
A Simulation Graphs

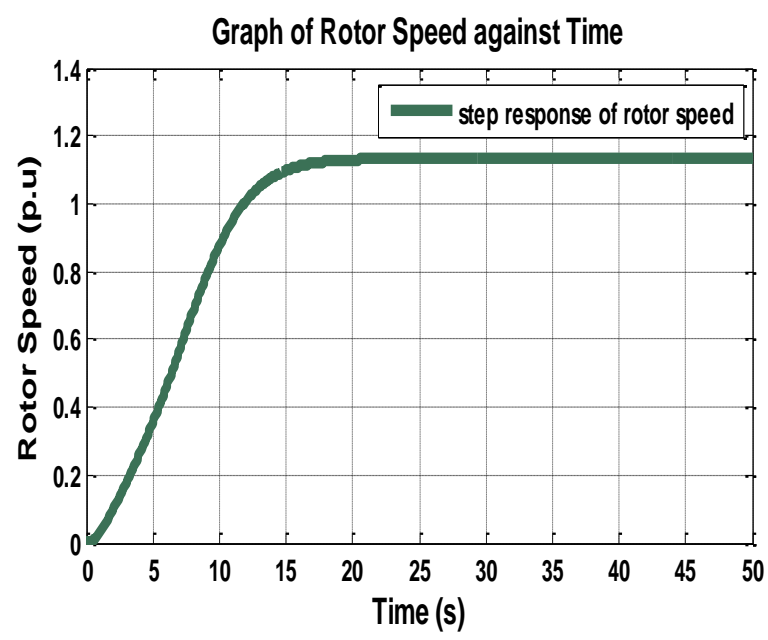

Fig. 5: Step response for speed control

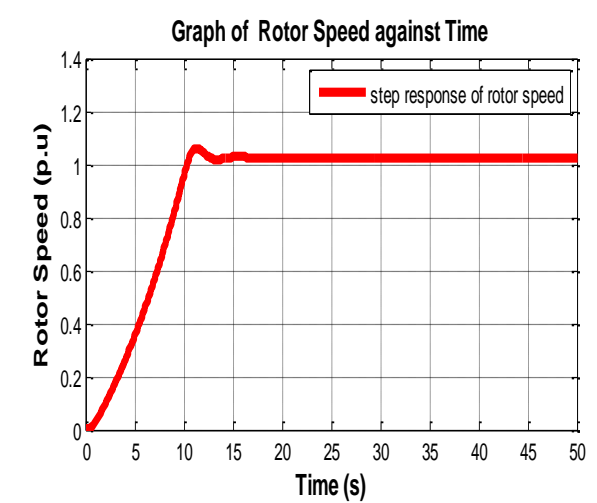

Fig. 6: Step response for speed control system (with no controller)

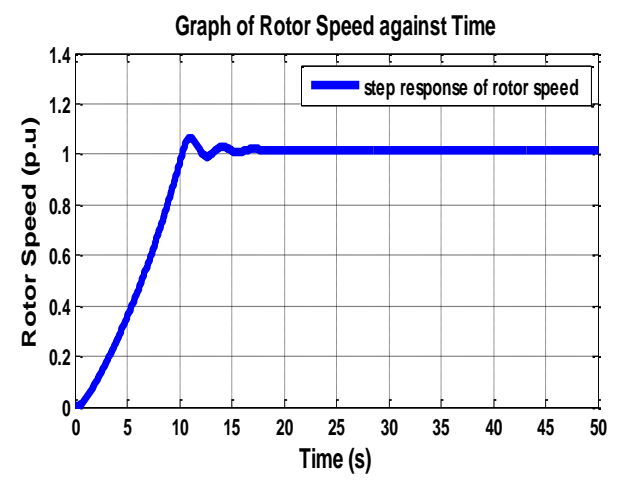

Fig. 7: Step response for speed control system (with compensator)

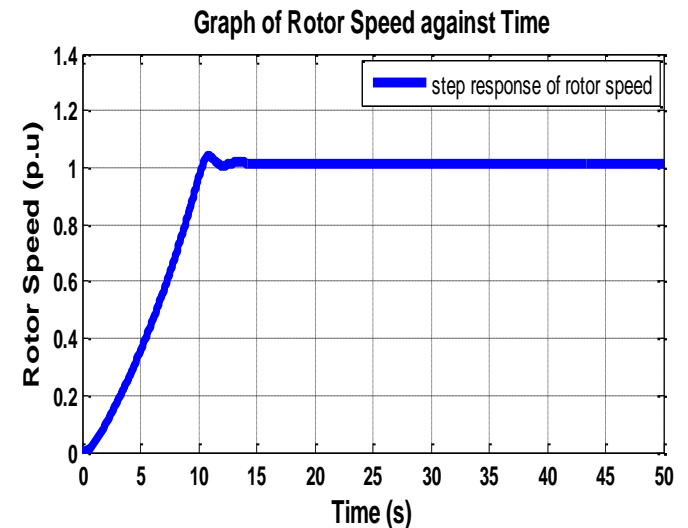

Fig. 8: Step response for speed control system (with PID controller) system (with PID integrating a filter)

\section{B Discussion}

The governor speed droop of $4 \%$ is used for the simulation, as shown in speed-load control block. The transient response time of the speed/load-frequency control has been presented in Fig. 5, 6, 7and 8. The operation of the speed control is based on the speed error formed when the HDGT rotor speed was compared with the referenced speed of one perunit (1p.u.). The speed error or deviation was fed to the controller which in turn produced the control signal to the fuel system. Figures. 6 and 7 are the simulation results for improved rotor speed. The main objective of this work is to design a proportional, integral and derivative (PID) controller that will improved the transient response of a HDGT in a refinery in Nigeria. The essence of the analogue controller is only to demonstrate the fact that the control loop developed in this context used a permanent droop of $4 \%$ which gave the speed governor gain of 25 (per unit MW/per unit speed). It is just a design approach. Hence the optimized compensator performance specifications were then maintain and used to develop a PID structure with the same performance but with improved tracking. In Figure. 8 the designed PID controller was improved by adding a low pass filter to the derivative component. This greatly improved the transient response time of Figure.7. The simulations results show that the introduction of the nonlinear PID controller significantly improved the transient response time of the system from $20 \mathrm{~s}$ to $10.5 \mathrm{~s}$.

The essence of the low pass filter is to eliminate any disturbance that may enter the system through the set point signal. In all cases, the load/frequency control loop has a settling time of 10.5 seconds and improved overshoot performance. The result shows that the performance of the optimized control system has been significantly improved compared to the loop without the controller. This signifies improved transient response.

Finally, with the nature of the transient response time shown in Fig.5, it is obvious that the system will sluggishly rise above the required rated load or full load (set point $=1$ p.u.). This, will to a large extent, affect the stability of the system at nominal operating condition. In order to take care of this problem and improve the performance of the system, a nonlinear PID controller was introduced as part of the control loop, and consequently improved the performance. 


\section{CONCLUSION}

This paper has presented a control system for improving the transient response time of speed/load-frequency of a gas turbine in a refinery in Nigeria. In order to realize the objective, the dynamic equations of a single shaft heavy duty gas turbine (HDGT) were obtained for load-frequency control operation. The dynamic equations were transformed into their equivalent simulink model in Matlab/Simulink environment. A lead phase compensator was initially developed for the control loop and maintaining the optimized performance specification, a proportional, integral and derivative (PID) controller was developed in Matlab/Simulink environment. A simple procedure in line with articles that have been published in literature was used for parameter estimation of Rowen's model for a practical HDGT. The obtained parameters for a 33MW HDGT were used for simulation tests and the obtained results are presented. The gains of the designed nonlinear PID controller was realized using Matlab/Simulink optimization toolbox rather than the Ziegler-Nichols. The nonlinear PID controller with a low pass filter was able to improve the transient response performance of the load-frequency control loop..

\section{REFERENCES}

[1] Saeed Bahrami , Ali Ghaffari and Marcus Thern (2013). Improving the Transient Performance of the Gas Turbine by Steam Injection during Frequency Dips, Energies 2013, 6, 5283-5296; doi:10.3390/en6105283

[2] Al-Hamouz Z. M, Abdel-Magid Y. L (1993). Variable-structure load frequency controllers for multi area power systems. Int. J. Electr. Power Energy Syst., 15(5): 23-29

[3] Chang C. S, Weihui Fu (1997). Area load frequency control using fuzzygain scheduling of PI controllers. Electric Power Syst. Res., 42: 145-152.

[4] Behnam Jamshidzadeh1 and Shahram Jamali (2011). An analysis on the application of PID controller in the frequency contribution of gas turbine power plant, International Journal of the Physical Sciences Vol. 6(19), pp. 4519-4527, 16 September, 2011 DOI: 10.5897/IJPS11.371, ISSN 1992 - 1950 @2011 Academic Journals

[5] Cohen H., Rogers G.F.C., Saravanamuttoo H.I.H. (1996). Gas Turbine Theory, 4th Edition, Longman, London.

[6] Harman R. T. (1981). Gas Turbine Engineering: Applications, Cycles and Characteristics, Macmillan, 1981, pp. 270.

[7] Rowen W. I (1983). Simplified mathematical representations of heavy-duty gas turbines, ASME J. Eng. Power, Vol. 105, pp. 865-869

[8] BankTavakoli M. R., Vahidi B., and Gawlik W. (2009). An Educational Guide to Extract the Parameters of Heavy Duty Gas Turbines Model in Dynamic Studies Based on Operational Data, IEEE Trans. Power Syst., Vol. 24, No.3. August 2009. 